\title{
Rapid estimation of the moment magnitude of the 2011 Tohoku-Oki earthquake (Mw 9.0) from static strain changes
}

\author{
Satoshi Itaba ${ }^{*}$ (i)
}

\begin{abstract}
The 2011 Tohoku-Oki earthquake, of moment magnitude $\left(M_{w}\right)$ 9.0, occurred on March 11, 2011, on the boundary between the Pacific and North America tectonic plates. The preliminary report of the magnitude announced by the Japan Meteorological Agency just after the earthquake was 7.9, which was considerably smaller than the final calculated Mw of 9.0. I used data from nine borehole strainmeters deployed by the National Institute of Advanced Industrial Science and Technology to estimate a fault model with $M_{w}$ of 8.7 for the 2011 earthquake. This model was estimated using data recorded during the first $7 \mathrm{~min}$ after the origin time of the earthquake $(5 \mathrm{~min}$ after the first P-wave arrival). To date, strainmeter data have rarely been used to derive earthquake fault models because observed strainmeter data often include noise caused by the local effect of earthquake shaking. My results indicate that strainmeter data can measure large changes of static strain that can be used to rapidly and precisely estimate earthquake fault models and moment magnitudes for great earthquakes and can provide an important and useful complement to analyses based on seismic waves.
\end{abstract}

Keywords: 2011 Tohoku-Oki earthquake, Moment magnitude, Strain, Borehole strainmeter, Crustal deformation

\section{Introduction}

The Tohoku-Oki earthquake, of moment magnitude $M_{\mathrm{w}}$ 9.0, occurred at 14:46 Japan standard time on March 11, 2011. Soon afterward, a giant tsunami struck the Pacific coast of eastern Japan and caused severe damage. Immediately after shaking commenced, the Japan Meteorological Agency (JMA) issued a preliminary report for the event that included a preliminary magnitude $\left(M_{\mathrm{JMA}}\right)$ of only 7.9. $M_{\mathrm{JMA}}$ is a magnitude scale based on the maximum amplitude observed on seismograms. However, for very large earthquakes, seismic records can be saturated, which compromises the use of maximum amplitudes to determine earthquake magnitudes. Because the discrepancy between the preliminary JMA magnitude and the final moment magnitudes was large, researchers have sought alternative methods for rapid magnitude determinations of great earthquakes. One such approach is based

*Correspondence: itaba-s@aist.go.jp

Geological Survey of Japan, National Institute of Advanced Industrial Science and Technology, 1-1-1 Higashi, Tsukuba, Ibaraki 305-8567, Japan on geodetic rather than seismic data. In this study, I used static strain changes measured by borehole strainmeters deployed by the National Institute of Advanced Industrial Science and Technology (AIST) to determine the magnitude of the Tohoku-Oki earthquake and compared my results with determinations based on other types of data.

\section{Observations}

For purposes related to forecasting Tokai, Tonankai, and Nankai earthquakes, AIST maintains 17 borehole observatories in the Tokai region, on the Kii Peninsula, and on the island of Shikoku; these observatories record groundwater levels and crustal deformation at a frequency of $20 \mathrm{~Hz}$ (Itaba et al. 2010). The depths of these wells range from 250 to $600 \mathrm{~m}$. Ishii-type multicomponent borehole strainmeters (Ishii et al. 2002) are installed at the bottom of 11 of these wells, of which 9 were operating when the 2011 Tohoku-Oki earthquake occurred. These strainmeters have four horizontal sensors and a vertical 
sensor. For this study, I used data from only the horizontal sensors.

The strainmeter sites were carefully chosen by AIST, and the strainmeters were installed in bedrock with few cracks, thus making the data recorded by the array precise enough to detect short-term slow-slip events on the plate boundary under the Kii Peninsula that are too small to be detected by either global navigation satellite systems (GNSS) or borehole tiltmeters (Itaba et al. 2010).

\section{Fault model (moment magnitude) estimations}

I quantified the static strain changes at the nine borehole observatories as follows. First, the $20-\mathrm{Hz}$ time-series data were resampled at 1 -min intervals by averaging values recorded $30 \mathrm{~s}$ before and after each minute. Second, the linear trend during the day of 11 March was removed. Examples of typical strain changes caused by the earthquake are shown in Fig. 1. The static strain change as a result of the earthquake is defined as the difference between the mean strain values for the 10 min immediately before the earthquake (14:35-14:45) and immediately after the earthquake (before 14:56, mean value from 14:47). The observed strain values were calibrated with observed and theoretical tidal changes at each observatory (Matsumoto et al. 2011). Matsumoto et al. (2011) also used teleseismic surface wave data to validate, and it is known that there is no such problem on the short period band.

To reliably discriminate regional tectonic strain signals from local noise near the sensors, I selected only coherent anomalies that were consistent among all four horizontal components at each station. The sensors of these components are installed at intervals of $45^{\circ}$ azimuth and about $25 \mathrm{~cm}$ vertical position, so that four sets of principal strains can be calculated from different combinations of three of the four sensors. Because an elastic strain field features strong geometric spreading that is inversely proportional to the cube of distance, variation among the sensors is negligible for a sufficiently distant tectonic strain source, but a nearby source imposes notable variation among the sensors. Thus, a strain anomaly of tectonic origin that is uniform around the sensors should result in four identical sets of calculated principal strains.

At eight of the nine stations, the four sets of observed principal strain were generally consistent (Fig. 2), but the data from site MYM showed a large variation among the four strain sets. I therefore excluded the results from site MYM. The analysis proceeded with data from the remaining eight stations.

From the estimated static strain changes, I inverted source fault locations on the top of the Pacific plate (Nakajima and Hasegawa 2006; Nakajima et al. 2009; Kita et al. 2010), basing the fault sizes and slip amounts on results of a grid searching procedure. This procedure used grid intervals of $0.1^{\circ}$ for both latitude and longitude; it assumed a single initial fault segment with width and length of $10 \mathrm{~km}$ and $0.5 \mathrm{~m}$ of homogeneous slip. The position of the fault was constrained to include the ruptures assumed for the earthquake early warning (EEW). The slip direction was assumed to be parallel to the subduction direction of the Pacific plate $\left(\mathrm{N} 115^{\circ} \mathrm{E}\right)$ (Wei and Seno 1998), and Green's function was calculated assuming a homogeneous half space (Okada 1992).

The fault model estimated by using data from each of the eight strainmeter stations is shown in Fig. 3.

\section{Results}

The fault model that I estimated for the mainshock of the 2011 Tohoku-Oki earthquake extends $100 \mathrm{~km}$ parallel to the plate boundary and $150 \mathrm{~km}$ parallel to the direction of subduction (Fig. 3) with slip of $21.5 \mathrm{~m}$ and a moment magnitude of 8.7. This magnitude is consistent with a fault model estimated by using RTK-GPS data for tsunami forecasting (e.g., Ohta et al. 2012).

I estimated fault models after the mainshock at intervals of 1 min (Fig. 4a). Comparison of the time series of magnitudes based on JMA EEW messages moment magnitudes based on RTK-GPS data and my analyses (Fig. 4b) shows that borehole strainmeter data can yield stable estimates of moment magnitude about $5 \mathrm{~min}$ after the mainshock (about $3 \mathrm{~min}$ after P-wave arrival at the boreholes). Note that calculation times are not included in these times. Our calculation times were about $10 \mathrm{~s}$, but these are dependent on the processing power of the computer used.

\section{Discussion}

Geodetic methods are widely used to derive fault models for large earthquakes because they cover longer-term crustal movements than those analyzed by seismic methods. The main types of geodetic modeling are based on GNSS, interferometric synthetic-aperture radar (InSAR), tiltmeter, and strainmeter measurements. GNSS and InSAR are effective for analyzing the distribution of fault slip, but the time resolution of InSAR data is low, whereas those of tiltmeter and strainmeter data are high. Tiltmeters, however, are sensitive to ground shaking. Strainmeters are less sensitive to ground shaking than tiltmeters, but observations of changes of coseismic strain have not been considered reliable because they often differ from theoretical values. For example, recent studies of borehole strain measured in California by using Gladwin tensor strainmeters (GTSMs) have shown systematic (Langbein 2015) and semi-random (Barbour et al. 2015) differences from theoretical strain values. 


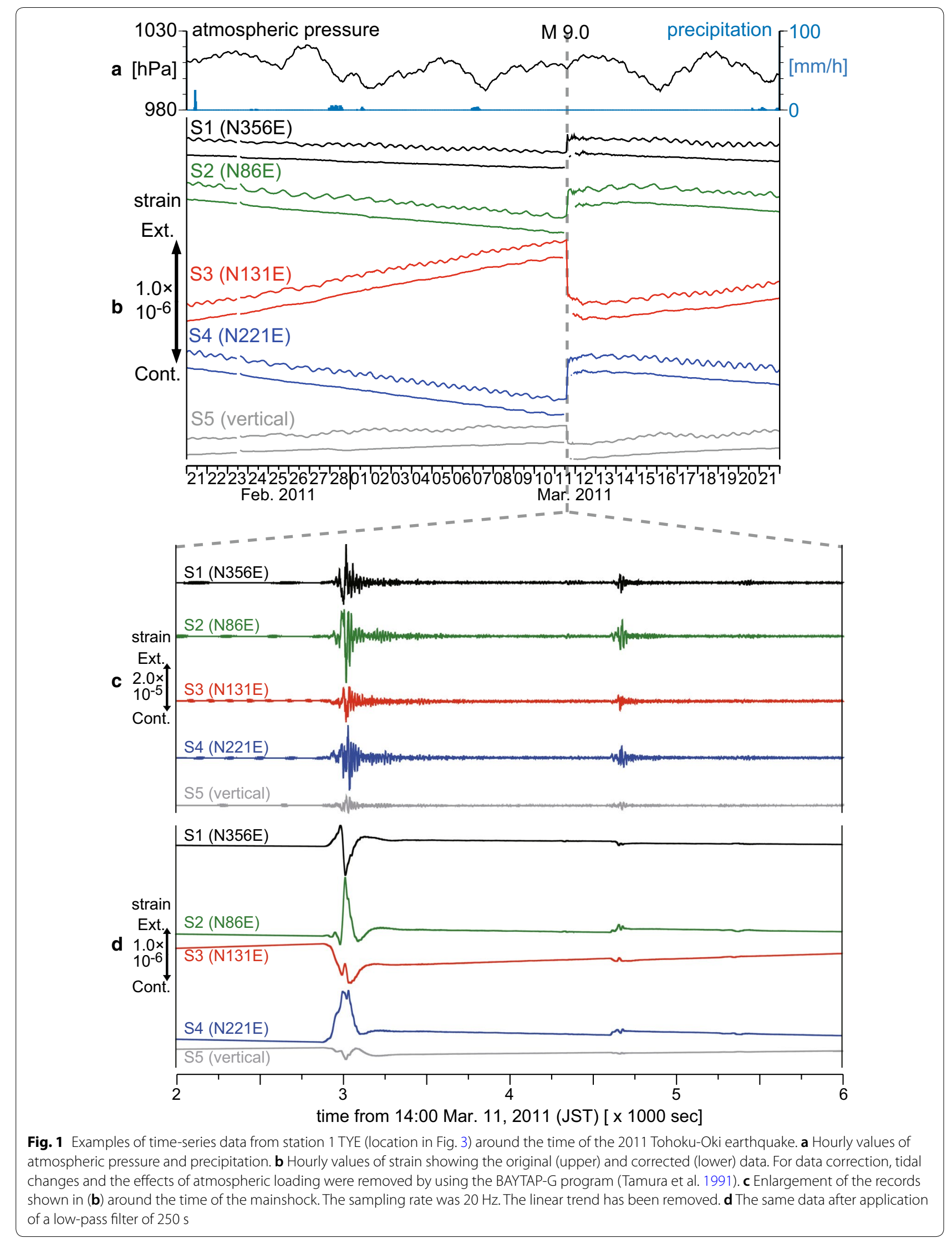




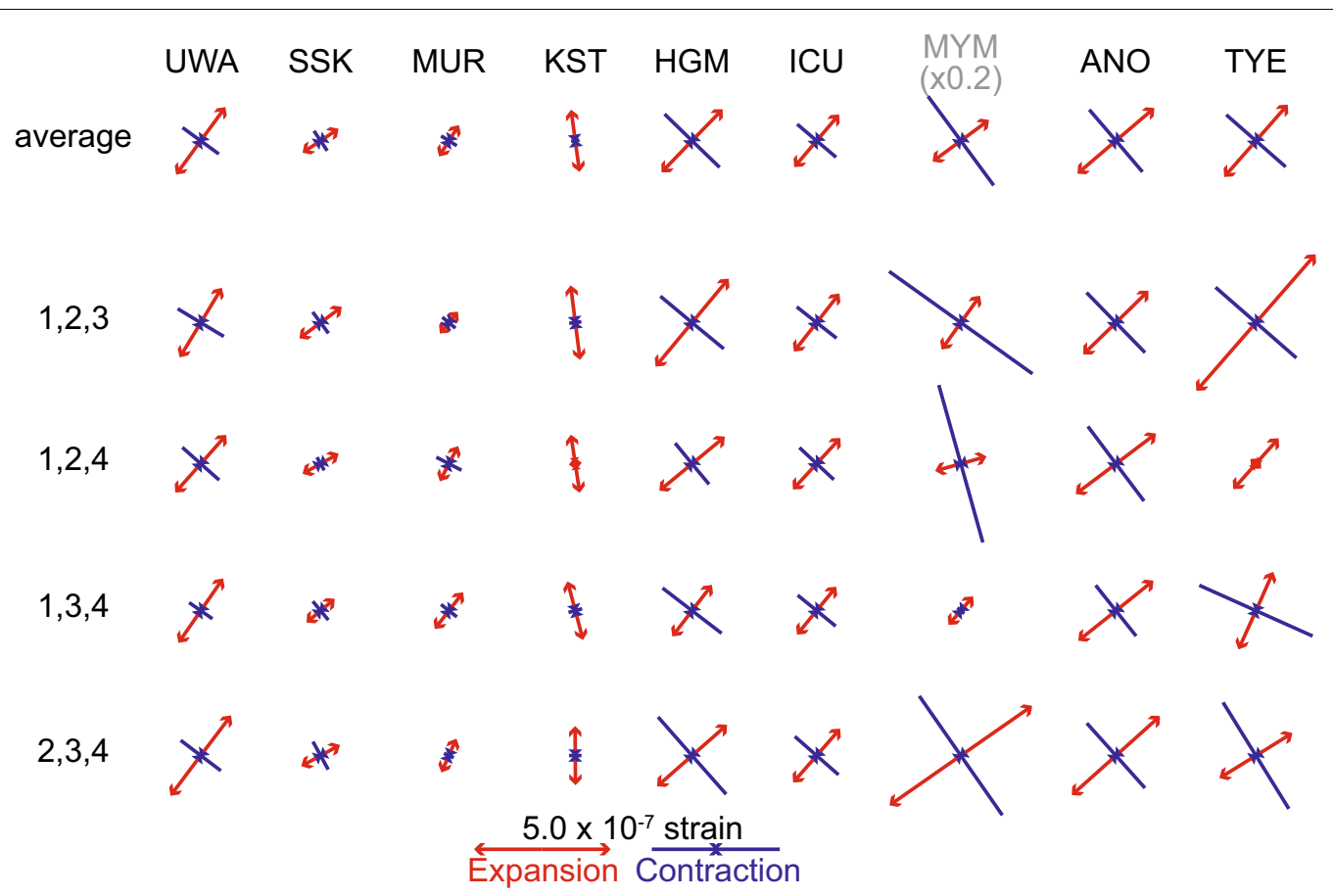

Fig. 2 Observed principal strain vectors at nine GSJ borehole stations. The four sets of principal strains are generally consistent for all stations except site MYM, for which the variation among the four sets is large owing to local noise
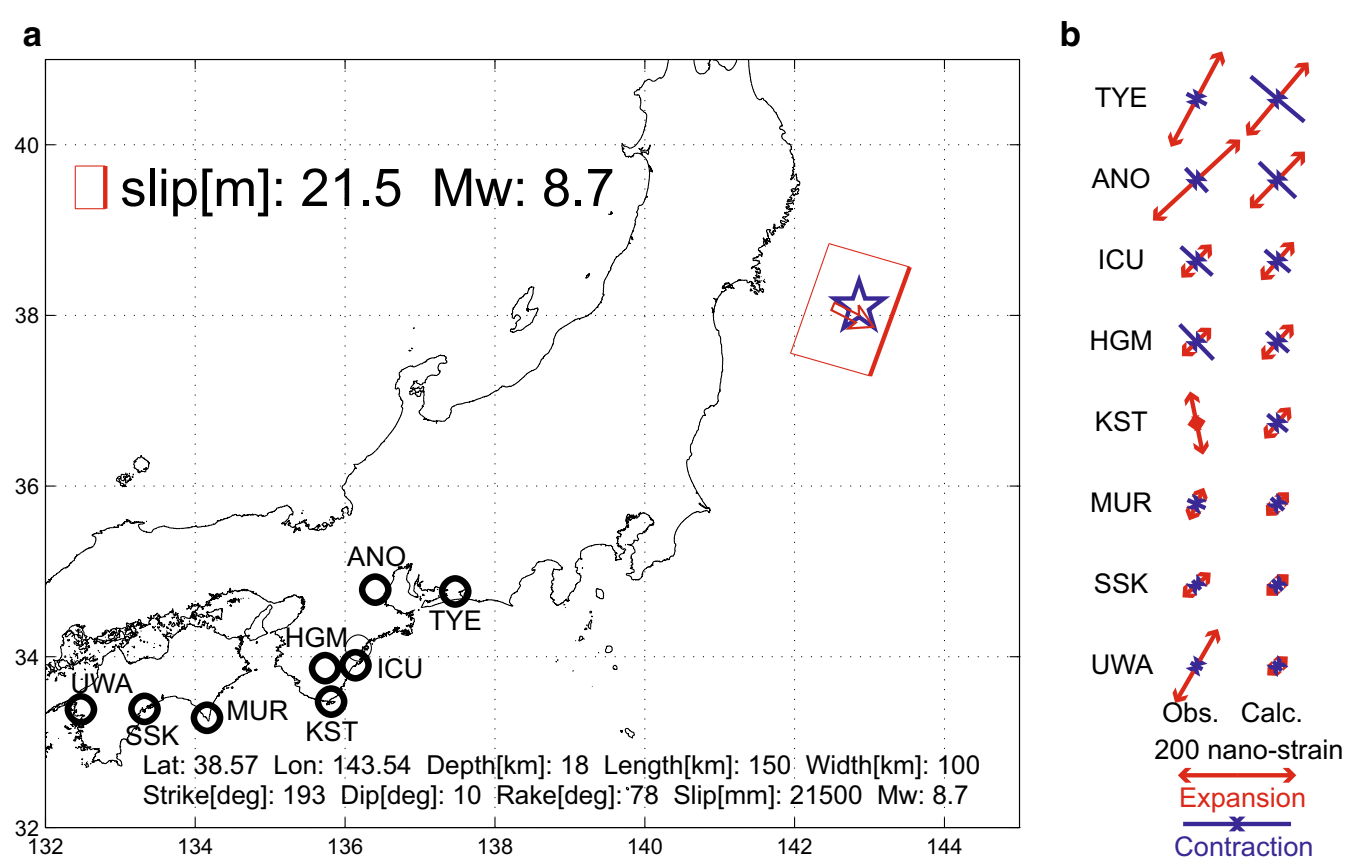

Fig. 3 a The estimated fault model for the 2011 Tohoku-Oki earthquake (red rectangle). The blue star marks the epicenter of the mainshock. The black bold circles show the borehole strainmeter sites. b Observed and calculated principal strain changes 
According to Roeloffs (2010), the use of GTSMs is problematic because vertical coupling can reduce apparent areal strain coupling coefficients. The AIST strainmeter array includes four GTSMs, AIST has confirmed that the same problem and are not used for analysis. The data used in this study were from Ishii-type strainmeters that employ a magnetic sensor. Tidal calibrations of data from Ishii-type borehole strainmeters by Matsumoto et al. (2011) show minimal vertical coupling.

Data from the AIST strainmeter array have also been used to monitor slow-slip events along the Nankai Trough, and it has been found that SSE occurs at a location consistent with the tremor occurrence area (e.g., Itaba et al. 2010; Itaba and Ando 2011).

For the above-stated reasons, I consider that the problems identified by Barbour et al. (2015) and Langbein (2015) are insignificant for analyses based on the instruments and methods used in this study. Furthermore, I avoided the effects of local noise by using tectonic signals recorded by four horizontal strain sensors. Thus, my results clearly show that the AIST borehole strainmeter array can measure large static strain changes precisely enough to enable short-term estimations of a fault models.

Although all of the strainmeters used in this study are distant from the source region and are clustered within one azimuthal quadrant relative to it, the moment magnitude I estimated for the 2011 Tohoku-Oki earthquake is consistent with fault models estimated from RTK-GPS data (Ohta et al. 2012). I believe that for rapid magnitude determinations of very large earthquakes, the geodetic method I used can provide an important complement to analyses based on seismic waves. The accuracy of the method I used may be improved by integrated analyses of strain and seismic data or by using more extensive strainmeter networks.

\section{Verification of the method}

To verify the usefulness of the method presented here, I applied it to several other earthquake events.

The first of these events was the largest aftershock of the 2011 Tohoku-Oki earthquake, which occurred $29 \mathrm{~min}$ after the mainshock. The preliminary report issued by JMA assigned this aftershock a magnitude of 7.3, whereas the moment magnitude I derived from borehole strain data was 7.6 (Fig. 5a), which is much closer to the final moment magnitude of 7.7 (JMA 2018).

I also examined the changes of static strain associated with three inland earthquakes that occurred around the
AIST strainmeter network: the foreshock and mainshock of the 2016 Kumamoto earthquake (final $M_{\mathrm{w}}$ values of 6.2 and 7.0, respectively; JMA 2018) and the 2016 Central Tottori earthquake (final $M_{\mathrm{w}}$ 6.2; JMA 2018). For these three events, I estimated only the width, length, and amount of slip of the source fault, and the moment magnitude.

For the foreshock of the 2016 Kumamoto earthquake, the preliminary JMA magnitude was 6.5 . The moment magnitude I derived from borehole strain data was 6.2, as was the final moment magnitude (JMA 2018) (Fig. 5b). For the mainshock of the 2016 Kumamoto earthquake, the preliminary JMA magnitude was 7.3 , the moment magnitude I derived from borehole strain data was 7.1, and the final moment magnitude was 7.0 (JMA 2018) (Fig. 5c). For the 2016 Central Tottori earthquake, the preliminary JMA magnitude was 6.6 , the moment magnitude I derived from borehole strain data was 6.0 , and the final moment magnitude was 6.2 (JMA 2018) (Fig. 5d).

In each of the four cases discussed above, the moment magnitude I derived from strainmeter data was close to the CMT solution derived by JMA (JMA 2018), and the observed and calculated principal strain values were consistent. These results show that borehole strainmeter data, with a redundant component, can be used to measure the changes of static strain that accompany fault displacement during earthquakes. Moreover, if the number of borehole observation points from which strain can be measured increases in the future, it will be possible to derive detailed fault models as well as moment magnitudes.

\section{Conclusions}

Changes of static strain related to the 2011 Tohoku-Oki earthquake on the boundary between the Pacific and North America tectonic plates were observed by an array of borehole strainmeters covering parts of the Tokai region, Kii Peninsula, and Shikoku Island. From these data, I estimated a time series of fault models to represent the 2011 earthquake. I demonstrated that it would have been possible to make a reasonable estimate of the moment magnitude of the 2011 Tohoku-Oki earthquake 5 min after the mainshock ( 3 min after the first P-wave arrival). The results of my study indicate that the AIST array of borehole strainmeters can measure large changes of static strain that can be used for rapid and precise estimation of earthquake fault models and moment magnitudes for great earthquakes and can provide an important complement to analyses based on seismic waves. 


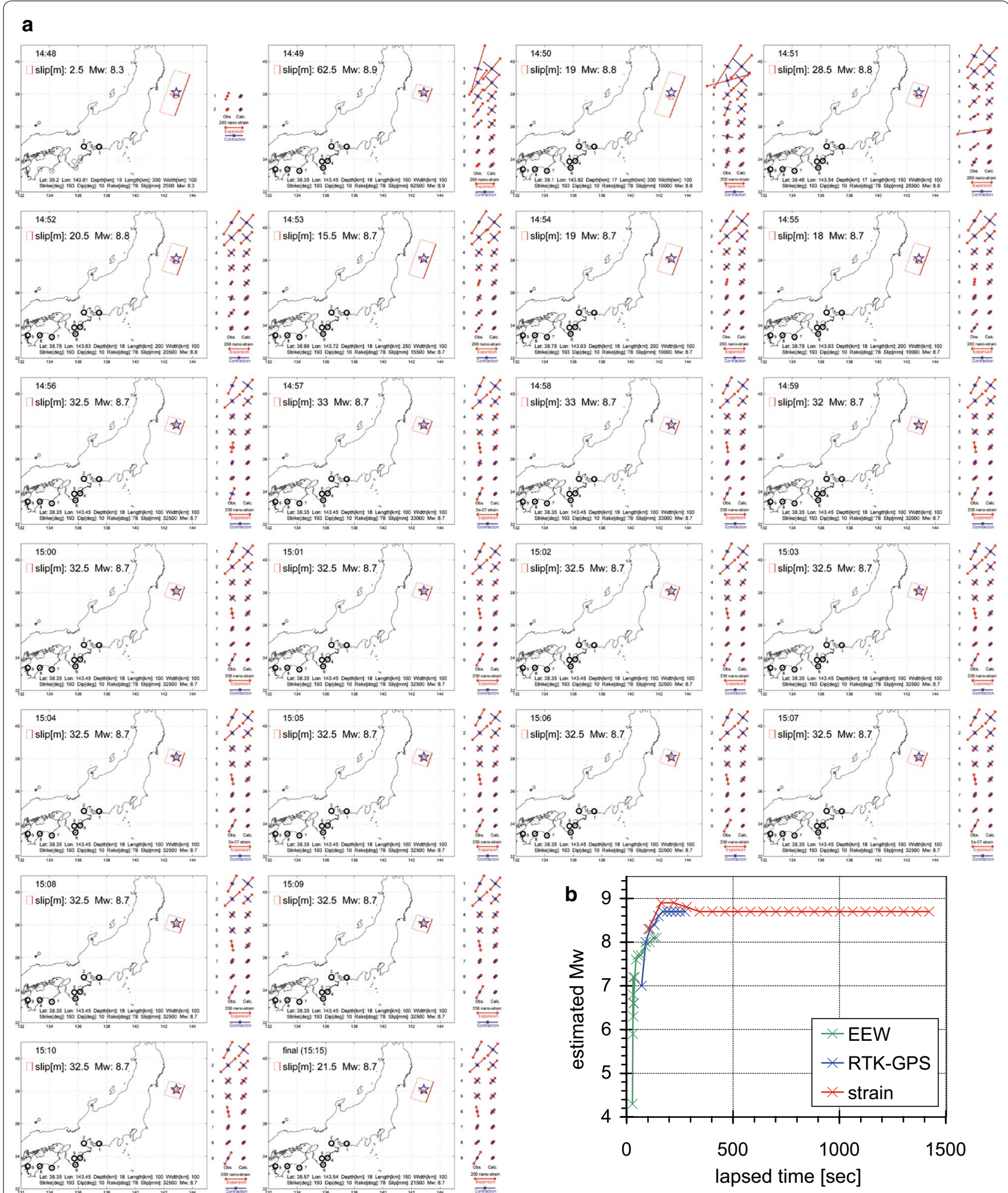

Fig. 4 a Snapshots of estimated fault model at 1-min intervals. Observed and calculated principal strains at the 8 stations that yielded usable data are shown at the right of each panel. $\mathbf{b}$ Time series of moment magnitude estimates based on EEW issued by JMA, RTK-GPS data (Ohta et al. 2012), and this study 

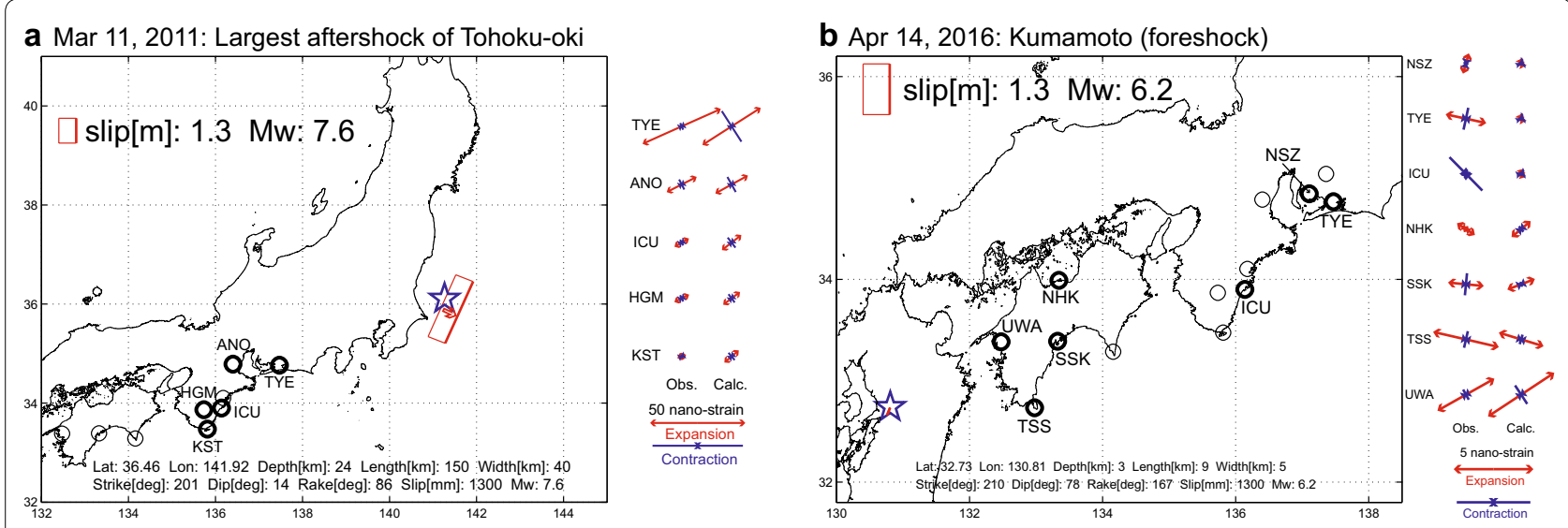

\section{Apr 16, 2016: Kumamoto (mainshock)}
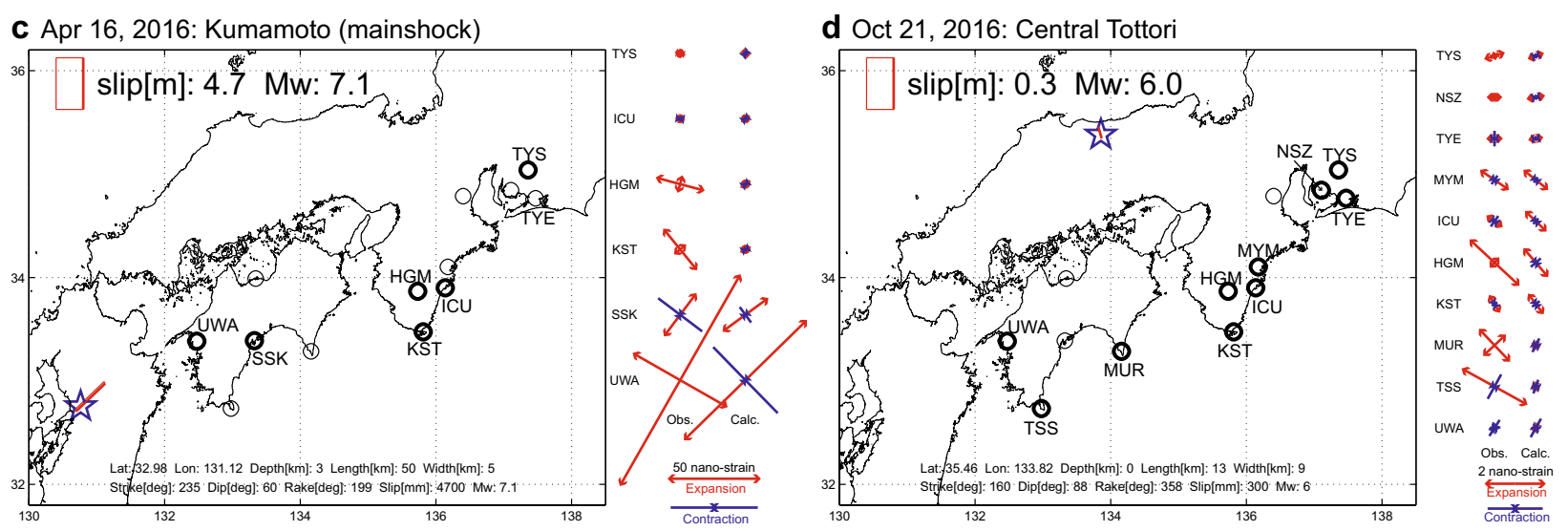

Fig. 5 Fault models (red rectangles) of four earthquakes estimated from borehole strain data, including observed and calculated principal strain changes at each station. a Largest aftershock of the $M_{w} 9.02011$ Tohoku-Oki earthquake. b Foreshock of the $M_{w} 6.02016$ Kumamoto earthquake. c Mainshock of the $M_{w} 7.02016$ Kumamoto earthquake. d 2016 Central Tottori earthquake ( $\left.M_{w} 6.2\right)$. Fault models in panels b, c, and d are nearly vertical, so the fault planes appear as single straight lines in those panels

\section{Abbreviations}

AIST: National Institute of Advanced Industrial Science and Technology; EEW: earthquake early warning systems; JMA: Japan Meteorological Agency.

\section{Authors' contributions}

The author performed the analysis and compiled, read, and approved the final manuscript.

\section{Acknowledgements}

We acknowledge the comments by Editor Takuya Nishimura and two anonymous reviewers, which improved the manuscript. Helpful discussions with Makoto Okubo are gratefully acknowledged. I am grateful to many people for their help in conducting observations at the borehole observatories.

\section{Competing interests}

The author declares that he has no competing interests.

\section{Availability of data and materials}

The data that support the findings in this study are available from the author on request.

\section{Funding}

The AIST strainmeter array was constructed by the grant-in-aid of facilities expense by Ministry of Economy, Trade and Industry (METI). This study was partially supported by MEXT KAKENHI Grant No. $15 \mathrm{H} 03713$.

\section{Publisher's Note}

Springer Nature remains neutral with regard to jurisdictional claims in published maps and institutional affiliations.

Received: 30 March 2018 Accepted: 20 July 2018

Published online: 31 July 2018

\section{References}

Barbour AJ, Agnew DC, Wyatt FK (2015) Coseismic strains on plate boundary observatory borehole strainmeters in southern California. Bull Seismol Soc Am 105:431-444. https://doi.org/10.1785/0120140199

Ishii H, Yamaguchi T, Matsumoto S, Hirata Y, Nakao S (2002) Development of multi-component borehole instrument for earthquake prediction study: Some observed examples of precursory and co-seismic phenomena relating to earthquake swarms and application of the instrument for rock mechanics. In: Ogasawara H, Yanagidani T, Ando M (eds) Seismogenic process monitoring. A.A. Balkema Publishers, Avereest, pp 365-377

Itaba S, Ando R (2011) A slow slip event triggered by teleseismic surface waves. Geophys Res Lett 38:L21306. https://doi.org/10.1029/2011GL0495 93

Itaba S, Koizumi N, Matsumoto N, Ohtani R (2010) Continuous observation of groundwater and crustal deformation for forecasting Tonankai and Nankai earthquakes in Japan. Pure Appl Geophys 167:1105-1114. https:// doi.org/10.1007/s00024-010-0095-z 
Japan Meteorological Agency Website (2018) The Seismological Bulletin of Japan. https://www.data.jma.go.jp/svd/eqev/data/bulletin/index_e.html. Accessed 09 July 2018

Kita S, Okada T, Hasegawa A, Nakajima J, Matsuzawa T (2010) Anomalous deepening of a seismic belt in the upper-plane of the double seismic zone in the Pacific slab beneath the Hokkaido corner: possible evidence for thermal shielding caused by subducted forearc crust materials. Earth Planet Sci Lett 290:415-426

Langbein J (2015) Borehole strainmeter measurements spanning the 2014 Mw6.0 South Napa Earthquake, California: the effect from instrument calibration. J Geophys Res Solid Earth 120:7190-7202. https://doi. org/10.1002/2015JB012278

Matsumoto N, Kamigaichi O, Kitagawa Y, Itaba S, Koizumi N (2011) Tidal calibration of borehole strainmeter using green's functions at the deployment depth. EGU General Assembly 2011. Geophysical Research Abstracts 13: EGU2011-1866-1

Nakajima J, Hasegawa A (2006) Anomalous low-velocity zone and linear alignment of seismicity along it in the subducted Pacific slab beneath Kanto, Japan: reactivation of subducted fracture zone? Geophys Res Lett 33:L16309. https://doi.org/10.1029/2006GL026773
Nakajima J, Hirose F, Hasegawa A (2009) Seismotectonics beneath the Tokyo metropolitan area, Japan: effect of slab-slab contact and overlap on seismicity. J Geophys Res 114:B08309. https://doi.org/10.1029/2008JB006101

Ohta Y, Kobayashi T, Tsushima H, Miura S, Hino R, Takasu T, Fujimoto H, linuma T, Tachibana K, Demachi T, Sato T, Ohzono M, Umino N (2012) Quasi realtime fault model estimation for near-field tsunami forecasting based on RTK-GPS analysis: application to the 2011 Tohoku-Oki earthquake (Mw 9.0). J Geophys Res 117:B02311. https://doi.org/10.1029/2011JB008750

Okada Y (1992) Internal deformation due to shear and tensile faults in a halfspace. Bull Seismol Soc Am 82:1018-1040

Roeloffs $E$ (2010) Tidal calibration of plate boundary observatory borehole strainmeters: roles of vertical and shear coupling. J Geophys Res 115:B06405. https://doi.org/10.1029/2009JB006407

Tamura Y, Sato T, Ooe M, Ishiguro M (1991) A procedure for tidal analysis with a Bayesian information criterion. Geophys J Int 104:507-516

Wei D, Seno T (1998) Determination of the Amurian plate motion in mantle dynamics and plate interactions in East Asia. Geodynam. Series ed. by M. Flower et al., vol 27, pp 337-346

\section{Submit your manuscript to a SpringerOpen ${ }^{\circ}$ journal and benefit from:}

- Convenient online submission

- Rigorous peer review

- Open access: articles freely available online

- High visibility within the field

- Retaining the copyright to your article

Submit your next manuscript at $\boldsymbol{\nabla}$ springeropen.com 